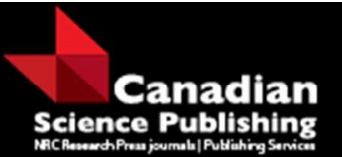

Canadian Journal of Forest Research

Revue canadienne de recherche forestière

\title{
Crown allometry and application of the pipe model theory to white spruce (Picea glauca (Moench) Voss) and aspen (Populus tremuloides Michx.) in the western boreal forest of Canada
}

\begin{tabular}{|r|l|}
\hline Journal: & Canadian Journal of Forest Research \\
\hline Manuscript ID & cjfr-2015-0165.R2 \\
\hline Manuscript Type: & Article \\
\hline Date Submitted by the Author: & 02-Nov-2015 \\
\hline Complete List of Authors: & $\begin{array}{l}\text { Sattler, Derek; University of Alberta } \\
\text { Comeau, Philip; University of Alberta, Renewable Resources }\end{array}$ \\
\hline Keyword: & $\begin{array}{l}\text { Pipe model, Crown allometry, Foliage mass, Picea glauca, Populus } \\
\text { tremuloides }\end{array}$ \\
\hline \multicolumn{2}{|l}{} \\
\hline
\end{tabular}


1 Crown allometry and application of the Pipe Model Theory to white spruce

2 (Picea glauca (Moench) Voss) and aspen (Populus tremuloides Michx.) in the

3 western boreal forest of Canada

4

5 Derek F. Sattler and Philip G. Comeau

6

7 Derek F. Sattler*. Department of Renewable Resources, University of Alberta, 751 General

8 Services Building, Edmonton, AB, T6G 2H1, Canada. Email: dsattler@ualberta.ca

9 Philip G. Comeau. Professor, Department of Forest Resources Management, University of

10 Alberta, 751 General Services Building, Edmonton, AB, T6G 2H14, Canada. Email:

11 pcomeau@ualberta.ca

12

13

14

15

16

17

18

${ }^{*}$ Corresponding author. Tel. 780-492-6472; fax. 780-492-4323. 


\section{Abstract}

White spruce [Picea glauca (Moench)] and aspen (Populus tremuloides Michx.) from unmanaged stands in the boreal forest of Alberta, Canada, were examined for two of the main

22 structural assumptions in the process-based model Crobas: 1) a constant allometric relationship

23 between foliage mass and crown length, and 2) a constant relationship between foliage mass and

24 sapwood area. We evaluated these relationships at both at the whole-crown and within-crown

25 levels. Results indicated that for both species, a constant allometric relationship between foliage

26 mass and crown length was maintained at the whole crown level over a period exceeding the

27 peak mean annual increment of each species. Within the crowns of spruce, foliage mass

28 accumulated faster near tree apex as total crown length increased. For aspen, the increase in

29 foliage mass per unit crown length for any section within the crown showed greater similarity to

30 the relationship observed at the whole crown level. The assumption of a constant relationship

31 between foliage mass and sapwood area at crown base held rather generally for spruce but

32 showed considerable variation for any given diameter class. For aspen, this assumption did not

33 appear to be appropriate. For both species, there was more foliage mass per unit sapwood area

34 with increasing height from the ground for nearly all tree size classes. This latter finding was in

35 conflict with the pipe model theory but could not be explained by the hydraulic theory of crown

36 architecture, which predicts a decrease in the ratio of foliage mass to sapwood area with

37 increasing path length.

38 Keywords: Pipe model, crown allometry, foliage mass, Picea glauca, Populus tremuloides 


\section{Introduction}

Crobas (Mäkelä 1997) is a process-based model which is based on the principle of carbon balance, but also incorporates principles related to the functional balance (Davidson 1969; Valentine and Mäkelä 2005). Among the structural regularities of trees that are assumed within the Crobas model, the two which have received considerable attention are: 1) that a constant allometric relationship exists between foliage mass $\left(W_{\mathrm{f}}\right)$ and crown length $(C l)$, and 2$)$ that the ratio of foliage mass to sapwood area at crown base $\left(A s_{\mathrm{cb}}\right)$ is invariant across tree size, social class and stand density.

Within Crobas, the relationship between foliage mass and crown length is used to obtain treelevel estimates of foliage mass, which in turn, are used to infer $A s_{\mathrm{cb}}$. By inferring foliage mass from crown length, the Crobas model ties the growth of the crown to the allocation of carbon within the tree (Mäkelä 1997). The assumption of a constant allometric relationship between foliage mass and crown length is supported by empirical observations from several tree species including Silver birch (Betula pendula L.) (Ilomäki et al. 2003), Norway spruce (Picea abies (L.) Karst.) (Kantola and Mäkelä 2006) and Scots pine (Pinus sylvestris L.) (Berninger and Nikinmaa 1994). Notably, Mäkelä and Sievänen (1992) postulated that the physiological basis for such a relationship is that it represents the optimal balance between added photosynthetic ability from increased foliage mass and the additional maintenance and respiration costs associated with a longer crown. However, it is acknowledged that the assumption of a constant allometric relationship between foliage mass and crown length is a generalization and findings from Mäkelä and Vanninen (1998) and Schneider et al. (2008), among others, have demonstrated that competition, tree size and age may influence this relationship. 
Notwithstanding the effects of age, size and competition, it is postulated that the exponent

62 parameter of the power allometric equation (Kittredge 1944) which describes the relationship

63 between foliage mass and crown length should lie between 2 and 3 (Zeide and Pfeifer 1991).

64 This range is an adjustment from the theoretical scaling exponent of 3, which is obtained if we assume that the crown is a fractal-like object formed by a volume filling branching network and is of constant shape (Mäkelä and Valentine 2006). The adjustment is supported by empirical observations of scaling between foliage mass and crown volume (Mäkelä and Vanninen 1998; Duursma et al. 2010).

There is sufficient evidence to suggest that the relationships described above cannot always be extended to describe scaling within the crown (Baldwin et al. 1997; Kantola and Mäkelä 2004). It is suggested that variation in the amount of foliage mass per unit crown length is related to the progressive increase in self-shading with increased distance from tree apex or increased competition from neighbouring trees; in practice, it is difficult to separate these two effects.

74 Within Crobas, these alterations need to be taken into account if within-crown estimates of foliage mass from crown-length are desired.

The assumption that there is a linear relationship between foliage mass and $A s_{\mathrm{cb}}$ is derived

77 from the pipe model theory of plant form (Shinozaki et al. 1964). Although the original pipe model proposed by Shinozaki et al. (1964) only makes reference to a relationship between foliage mass and active xylem, this has been taken to imply that the relationship can be extended

80 to $A s_{\mathrm{cb}}$, given the role of sapwood in supplying water and nutrients to foliage in the crown.

81 Following an initial estimate of foliage mass from crown length, the pipe model relationship is used within Crobas to estimate $A s_{\mathrm{cb}}$. Several empirical studies support the assumption of a linear

83 relationship between foliage mass and $A s_{\mathrm{cb}}$, (Kaipiainen and Hari 1985; Eckmullner and Sterba 
84 2000), while others have found the relationship to vary according to tree size, site productivity or 85 geographic location (Gilmore et al. 1996; Berninger et al. 2005). Nevertheless, among the tree's structural relationships, the pipe model appears to be the most stable.

The relationship between foliage mass and sapwood area has also been found to be maintained at all heights within the crown (Waring et al. 1982). However, a linear relationship between foliage mass and $A s_{\mathrm{cb}}$ does not necessarily imply a linear relationship within the crown (Schneider et al. 2011). This inconsistency may be due to the re-activation of disused pipes or a lag in time between the disuse of pipes and changes in foliage mass within the crown. Hydraulic path length may also be a factor. For example, the model of hydraulic architecture described by Whitehead and Jarvis (1981) and Whitehead et al. (1984a) has been used to explain within-tree variation in the relationship between foliage area and sapwood area (Medhurst and Beadle 2002). The hydraulic model predicts that the ratio of leaf area to sapwood area should decrease with increasing distance from ground due to increasing hydraulic resistance. Substituting foliage mass for foliage area, the hydraulic model may be used to describe within-crown variations in the pipe model ratio. However, such an argument requires specific leaf area $\left(\mathrm{cm}^{2} / \mathrm{g}\right)$ to remain stable from the tip to the base of the crown.

For the current study, we examine two main structural regularities assumed by the Crobas model for white spruce [Picea glauca (Moench)] and aspen (Populus tremuloides Michx.). These two disparate species are a major component of upland stands within the Western Canadian Boreal forest. White spruce is characterized as a shade tolerant, late successional species which maintains a large crown ratio (crown length : total tree height) throughout most of its development. Aspen, on the other hand, is a shade intolerant early successional species which maintains a relatively small crown ratio following crown closure. As a first main objective, we 
107 test for constant allometric scaling between foliage mass and crown length for these two species.

108 We then examine the relationship between foliage mass and crown length for sections within-

109 crown and contrast them to the relationships seen at the whole crown level. As a second main

110 objective, we test the assumption of a linear relationship between foliage mass and $A s_{\mathrm{cb}}$, which is

111 derived from pipe model theory. We then test the null hypothesis that predictions of foliage mass

112 from $A s_{\mathrm{cb}}$ under the assumption of the pipe model are dissimilar to observed values. Finally, we

113 look at the within-crown relationship between cumulative foliage mass and sapwood area. We

114 examine this relationship within the framework of the pipe model theory and contrast it with the

115 relationship viewed within the framework of the hydraulic model. The results of this study will

116 contribute to the evaluation of the Crobas model for use on white spruce and aspen within the

117 western Canadian boreal forest. The importance of process-based models such as Crobas in

118 directing forest management activities has been well documented (Mäkelä et al. 2000; Valentine

119 and Mäkelä 2005).

120 Material and methods

121 Site description

122 The sampling of trees used in this study was performed adjacent to Permanent Sample Plots

123 (PSPs) which had previously been installed by Alberta Sustainable Resource Development

124 (ASRD 2005). All PSPs were situated within unmanaged stands that had been established

125 through natural regeneration. Although the selected PSPs span approximately 500 kilometers

126 along an east-west latitude, climatic conditions over this region are reported to be similar

127 (Beckingham and Archibald 1996). All stands in which the sampled PSPs are located were

128 classified to the 'reference' ecosite-type (i.e., upland forests with moderately well-drained, othic-

129 gray luvisolic soils) of the central mixedwood natural subregion of Alberta, Canada 
130 (Beckingham and Archibald 1996). Given the common climatic conditions and ecosite-type, site 131 index values were assumed to be relatively similar.

132 Field and laboratory measurements

133 In total, 65 white spruce trees from 15 PSPs and 46 aspen trees from 12 PSPs were felled 134 (Table 1). The process of selecting trees to be felled for biomass sampling is described in Sattler 135 et al. (2014). Briefly, however, trees were selected in order to provide a range in sizes $(D B H)$ and 136 tree ages (cambial age at $B H$ ) for the given plot. Once felled, all live branches greater than 0.3 $137 \mathrm{~cm}$ in diameter at the point of insertion with the main stem (9332 branches) were measured for 138 branch diameter, branch angle, and location along the main stem. A subsample of 6 branches on 139 each felled tree was then randomly selected after first dividing the live crown in two equal halves 140 (3 in the upper half and 3 in the lower half). Subsampled branches were first measured for total 141 branch length $\left(H_{b}(\mathrm{~cm})\right)$ and then collected in bags and brought to a lab for further processing. 142 At the lab, foliage was separated from woody components. From each of the sampled branches, 143 an estimate of specific leaf area $\left(\mathrm{cm}^{2} / \mathrm{g}\right)$ was calculated by scanning a subsample of the foliage 144 using WinSeedle (for spruce) and WinFolia (for aspen) (Regent Instruments Inc. 2003, Québec, 145 Canada). All foliage was then oven dried (minimum 72hours @ 70C) and weighed. Sapwood in 146 the tree bole was measured on discs cut at crown base, mid-crown, half-way between crown base 147 and mid-crown and finally half-way between mid-crown and the apex of the crown. Sapwood 148 widths were measured at four orthogonal points after holding the discs up to a light source and 149 tracing around the darkened heartwood centre. 
151 Scaling up from branch to tree

152 To scale-up measurements of foliage mass (see Table 2 for variable descriptions) from

153 branch to tree, we developed a nonlinear mixed effect model which included both plot and tree-

154 level random effects. The species-specific models were fitted using data collected from

155 individual branches. For white spruce and aspen, the models performed quite well with adjusted-

$156 R^{2}$ values ( $68 \%$ for spruce; $86 \%$ for aspen) comparable to those reported by (Kantola and Mäkelä

157 2004) and (Ceulemans et al. 1990). Details of the model construction and associated fit statistics

158 are provided in Appendix 1. For each species, the fitted model was used to calculate foliage mass

159 for all live branches $>=3 \mathrm{~mm}$. Tree-level totals for foliage mass were obtained by summing across

160 all branches within a tree.

161 Table 2

162 Whole crown allometry

163 Tests for a constant or variable allometric relationship (CAR or VAR, respectively) between $164 W_{\mathrm{f}}$ and $\mathrm{Cl}$ were performed using the following two equations:

$165[1] \quad \hat{W}_{\mathrm{f}}=\delta_{0} C l^{\delta_{1}}+\varepsilon_{1}$

$166[2] \quad \hat{W}_{\mathrm{f}}=\delta_{0} C l^{\delta_{1}} \exp ^{C l \delta_{2}}+\varepsilon_{2}$

167 Where $\hat{W}_{\mathrm{f}}$ and $C l$ are as previously defined and $\delta_{0}, \delta_{1}$ and $\delta_{2}$ are parameters to be estimated from 168 the data. For both Equation 1 and Equation 2, $\delta_{0}$ is the rate parameter, while $\delta_{1}$ is the scale 169 parameter. Equation 1 assumes constant allometry, while Equation 2 is formulated following 170 Ruark's variable allometric equation (VAR) (Ruark et al. 1987). If the relationship is constant, 171 then there should be no improvement in model performance between Equation 1 and Equation 2. 172 Furthermore, estimates resulting from Equation 1 should be unbiased across $\mathrm{Cl}$. Since the 
173 competitive status of the tree may influence scaling between $\hat{W}_{\mathrm{f}}$ and $C l$, residuals were also

174 examined across the basal area of larger trees $(\mathrm{Bal})$. Equations 1 and 2 were fitted using a power

175 variance weighting structure that was a function of $\mathrm{Cl}$. Comparisons between Equations 1 and 2

176 were performed using likelihood ratio tests and adjusted- $R^{2}$ values.

177 Within-crown allometry

178 To contrast within-crown scaling between foliage mass and crown length with that observed

179 at the whole crown level, we first dividing total $C l$ into four equal sections $(k=1,2,3,4)$; where 1

180 is the top section and 4 is the section at the base of the live crown. Under the assumption that

181 scaling at the whole crown level follows Equation 1, then one should be able to estimate foliage

182 mass for the $k$-th crown section as:

$183 \quad[3] \quad \hat{W}_{\mathrm{f}_{k}}=\varphi_{k}\left(C l_{k}^{\delta_{1}}-C l_{k-1}^{\delta_{1}}\right)$

184 where $\hat{W}_{\mathrm{f}_{k}}$ is the foliage mass of the $k$-th crown section, $C l_{k}$ is the crown length from the crown 185 apex to the base of section $k$, and $C l_{k-1}$ is the crown length from the crown tip to the base of 186 section $k-1$. The parameter $\varphi_{k}$ is to be estimated while $\delta_{1}$ is derived from Equation 1, assuming 187 constant allometry. Thus, moving from the top crown section to the bottom of the crown, foliage 188 mass for each section was estimated by fitting the following set of equations:

$189 \quad[3 \mathrm{a}] \quad \hat{W}_{\mathrm{f}_{1}}=\varphi_{1} C l_{k}^{\delta_{1}}$

190

[3b] $\quad \hat{W}_{\mathrm{f}_{2}}=\varphi_{2}\left(\mathrm{Cl}_{2}^{\delta_{1}}-\mathrm{Cl}_{1}^{\delta_{1}}\right)$

$191[3 \mathrm{c}] \quad \hat{W}_{\mathrm{f}_{3}}=\varphi_{3}\left(\mathrm{Cl}_{3}^{\delta_{1}}-\mathrm{Cl}_{2}^{\delta_{1}}\right)$

$192 \quad[3 \mathrm{~d}] \quad \hat{W}_{\mathrm{f}_{4}}=\varphi_{4}\left(\mathrm{Cl}_{4}^{\delta_{1}}-\mathrm{Cl}_{3}^{\delta_{1}}\right)$ 
193 If constant allometric scaling is observed at the whole crown-level, then we should see $\varphi_{k}=$

$194 \delta_{0}$ for all $k$. Summing across Equations $3 \mathrm{a}$ to $3 \mathrm{~b}$ should, therefore, yield:

$195[3 \mathrm{e}] \quad \hat{W}_{\mathrm{f}}=\delta_{0} \mathrm{Cl}_{4}^{\delta_{1}}=\varphi_{4} \mathrm{Cl}_{4}^{\delta_{1}}$

196 A power variance weight function was used to fit Equations 3a to 3d, while residual plots were 197 used to identify bias. Model performance was assessed with adjusted- $R^{2}$.

198 Whole-crown foliage mass from pipe model theory

199 Using pipe model theory, the following equation was fitted to the spruce and aspen data:

$200 \quad[4] \quad \hat{W}_{\mathrm{f}}=\alpha_{0} A s_{\mathrm{cb}}+\varepsilon_{4}$

201 where $\hat{W}_{\mathrm{f}}$ is as previously defined, $A s_{\mathrm{cb}}\left(\mathrm{cm}^{2}\right)$ is sapwood area at the base of the live crown and $202 \alpha_{0}$ is the pipe model ratio. Our evaluation of the pipe model for use on spruce and aspen was 203 conducted using equivalence testing as described by Robinson et al. (2005). The equivalence 204 tests were performed for the whole dataset as well as by diameter class. Tests of the null 205 hypothesis of dissimilarity on the intercept were used to test for lack of bias, while tests of the 206 null hypothesis of dissimilarity on the slope was used to test for appropriate association between 207 measured and predicted values. As a region of equivalence, we began with $+-10 \%$ for the 208 intercept and $+-10 \%$ for the slope, and increased the region in increments of $5 \%$ until we could 209 reject the null hypothesis of dissimilarity. As a point of comparison for the pipe-based models,

210 we calculated $\hat{W}_{\mathrm{f}}$ using $D B H$ and height-based equations from the parameters provided by

211 Manning (1984; for white spruce) and Alemdag (1984; for aspen); in both cases, the published 212 parameters were suitable for the range of tree sizes in the current study. The same equivalence 213 tests were then performed on the resulting predictions. 
214 Within-crown foliage mass from pipe model theory

215 To examine within-crown scaling between cumulative $\hat{W}_{\mathrm{f}}$ and sapwood area along the stem,

216 the ratio of these two variables at the base of the $k$-th crown section was calculated as:

217 [5] $R p_{k}=\frac{\sum_{1}^{\mathrm{k}} \hat{W}_{\mathrm{f}_{k}}}{A s_{k}}$

218 where $R p_{k}$ is the ratio between cumulative $\hat{W}_{\mathrm{f}_{k}}$ and $A s_{k}$ at the base of the $k$-th crown quarter

219 section. To test the assumption that the pipe model ratio remains constant within the crown, $R p_{k}$

220 was plotted against the relative position within the crown (Rdinc; $0=$ tree apex, $1=$ crown base),

221 with the relationship fitted using a linear regression. Potential effects of size class on the

222 relationship were addressed by fitting a separate regression for each diameter class. As a

223 complimentary tests, the relative position within the crown was replaced with the height $(\mathrm{m})$ to

224 the base of the $k$-th crown quarter section $\left(H_{k}\right)$ and regression equations again fitted for each

225 diameter class. For each independent variable, the linear regression used was:

226

$\quad R p_{k}=\lambda_{0, \text { dclass }}+X_{k} \lambda_{1, \text { dclass }}+\varepsilon_{6}$
$X=$ Rdinc, $H_{k}$

227 Under the assumption of a constant pipe model ratio, $\lambda_{1}$ should be zero, regardless if Equation 6

228 is fitted using Rdinc or $H_{k}$. However, support for the hydraulic model may been found if $\lambda_{1}$ is

229 negative and significant when Equation 6 is fitted using $H_{k}$ given that $R p_{k}$ is said to decrease

230 with increasing hydraulic path length (represented here by $H_{k}$ ). As was done in previous

231 equations, heteroskedasticity and correlation between observations were addressed when fitting

232 Equation 6. 
As final step, trends in specific leaf area from tree top to crown base for both spruce and

234 aspen were examined using a set of linear regressions. The analysis of vertical trends for specific

235 leaf area was included since an increase in specific leaf area from tree apex to crown base would

236 impact our ability to draw comparisons between expected trends under the pipe model ratio

237 (which uses foliage mass) and those expected under the hydraulic model (which uses foliage

238 area).

Following Marshall and Monserud (2003), specific leaf area was modelled as:

[7] $S L A=\eta_{0}+C r d p t h * \eta_{1}+\varepsilon_{7}$

241 where $S L A$ is the specific leaf area $\left(\mathrm{cm}^{2} / \mathrm{g}\right), C r d p t h$ is crown depth from tree apex, and $\eta_{0}$ and

$242 \eta_{1}$ are parameters to be estimated. For both spruce and aspen, Equation 7 was fitted separately for

243 each diameter class. Parameters for Equation 7 and all previous equations were estimated using

244 the gnls function (generalized nonlinear least squares) in the nlme package (Pinheiro et al. 2015)

245 for R (R Core Team 2013).

246 Results

247 Foliage mass and crown length: whole crown allometry

248 The estimated parameters and fit statistics for the CAR (Equation 1) and VAR (Equation 2)

249 models for spruce and aspen are presented in Table 3. Likelihood ratio tests and values for the

250 RMSE indicated that for both spruce and aspen, the VAR model was not superior to the CAR.

251 Thus, for both spruce and aspen, scaling between foliage mass and crown length appeared to be

252 constant over increasing crown length. For spruce, the CAR model indicated that foliage mass

253 scaled with crown length with an exponent of 1.45 (Figure 1a), while for aspen the exponent was

2541.29 (Figure 1b). For both species, the residuals resulting from the CAR model showed no trends 
255 across crown length. However, for spruce, there was noticeable bias when the residuals were 256 plotted against Bal. Specifically, the CAR model under-estimated foliage mass on trees in a 257 dominant position and over-estimated foliage mass for trees in a suppressed position. For aspen, 258 there were no trends in the residuals when plotted across $\mathrm{Bal}$.

259 Table 3

Figure 1.

260 Foliage mass and crown length: within-crown allometry

261 For spruce, the results of Equation 3a to $3 \mathrm{~b}$ suggest that the constant allometry observed at 262 the whole crown level is not observed for individual sections within the crown. For the section $26375 \%$ to crown base, $\varphi_{4}$ was significantly lower than the value for $\delta_{0}$ observed at the whole 264 crown level (Table 4). With increasing crown length, the increase in foliage mass near to base of 265 the crown was lower than all other sections of the crown (Figure 2). In the top half of spruce 266 crowns, values for $\varphi_{k}$ were significantly greater than that observed at the whole crown level 267 indicating that as the crown length increased, the increase in foliage in these sections was higher 268 than in other parts of the crown. At 50\% to $75 \%$ from the crown apex, the increase in foliage 269 mass with increasing crown length was closest to that observed at the whole crown level.

270 However, there was considerable variability between trees as indicated by the low adjusted- $R^{2}$

271 value (Table 4). Analysis of the residuals revealed that there was minimal bias across Bal in the 272 top quarter section of the crown. Bias in relation to Bal, however, was evident within all three 273 lower crown quarter sections, with trends in the residuals mirroring those from the CAR model 274 fitted to the whole-crown (Figure 3).

275 Table 4 
For aspen, constant allometric scaling in individual crown sections generally seemed to hold.

277 For the section $75 \%$ to crown base, foliage mass increased with increasing crown length at a rate

278 similar to that at the whole crown level given that $\varphi_{4}=\delta_{0}$. The middle crown sections $(25-50 \%$

279 and 50-75\%) displayed the greatest increase in foliage mass with increasing crown length, while

280 the rate of increase was much lower in the top crown section (Figure 2). For each crown section,

281 the estimates of foliage mass did not appear to be biased with respect to Bal (Figure 4).

Figure 2.

Figure 3.

Figure 4.

282 Pipe model ratio: whole-crown allometry

283 The estimated pipe model ratio in Equation $4\left(\alpha_{0}\right)$ was $0.14(\mathrm{SE}=0.005)$ for spruce and 0.03

$284(\mathrm{SE}=0.001)$ for aspen. The pipe model explained a far greater proportion of the variability in

285 foliage mass for spruce (Adj. $R^{2}=69 \%$; RMSE=7.48 Kg; bias=-0.11) than for aspen (Adj.-

$286 R^{2}=25 \% ; \mathrm{RMSE}=1.09 \mathrm{Kg} ;$ bias=-0.19). When fitted to the dataset containing all diameter

287 classes, equivalence tests on the intercept (test of bias) and the slope (test of accuracy) had a

288 smaller minimum region to reject the null hypothesis of dissimilarity for spruce than for aspen

289 (Table 5). For individual diameter classes, equivalence tests on the intercept for spruce showed

290 comparable results to that found for aspen, with minimum regions of rejection between 15 and

$29140 \%$. However, tests on the slope indicated that the pipe model tended to provide greater

292 accuracy in estimates of foliage mass for spruce than for aspen. For any one diameter class, we

293 judged the regions of equivalence required to reject the null hypothesis for the slope to be quite

294 large for both spruce and aspen. Nevertheless, there was stronger evidence in favour of the pipe 
295 model than the regionally calibrated $D B H$ and height-based equations provided by Manning et al.

296 (1984) and Alemdag (1984) (Table 5).

$297 \quad$ Table 5

298 Pipe model ratio: within-crown allometry

299 For spruce, the pipe model ratio $\left(R p_{k}\right)$ showed some variation over relative position within

300 the crown (Figure 5). However, the linear regressions for each diameter class revealed that the

301 slope of the relationship was not significant (Equation 6; Table 6), thus, lending support to the

302 assumption that the pipe model ratio remains more-or-less constant within the crown, regardless

303 of tree size. Similarly, the pipe model ratio within the crowns of small trees appeared unchanged

304 with increasing distance from ground (Figure 5). However, regression analysis revealed that the

305 pipe model ratio increased with increasing distance from the ground within the crowns of trees

306 from all other diameter classes. This latter finding, therefore, suggested that the ratio was

307 affected by increasing hydraulic path length.

308 Table 6

With Equation 6 fitted to the aspen data using relative position in the crown as the

310 independent variable in Equation 6, there was a tendency for the pipe model ratio to decrease

311 from crown apex to crown base in the smallest two diameter classes. No significant trends were

312 noted in the larger two diameter classes (Table 6). When relative position was replaced by

313 absolute distance from the ground in Equation 6, there was a clear tendency for the pipe model

314 ratio to increase with increasing height in all but the smallest diameter class. As with spruce, the

315 variability in the ratio was high with the significant fitted regressions explaining only $8 \%$ and

$31618 \%$ of the within-crown variability for the two largest diameter classes. 
Figure 5.

Figure 6.

317 For both spruce and aspen, the variability in specific leaf area from tree apex to crown base 318 was quite large for any one diameter class. Results from Equation 7 revealed that for white 319 spruce, there was no significant relationship between specific leaf area and crown depth

320 (Crdpth) (Table 7). For aspen, there was a significant increase in specific leaf area from crown 321 apex to crown base for all diameter classes.

322 Table 7.

\section{Discussion}

324 Foliage mass - crown length allometry

325 That whole-crown foliage mass in spruce showed constant allometric scaling with crown 326 length was unexpected. Given the low self-pruning of branches, high needle retention and a 327 reduction in height growth with age, our prior expectation was that the largest and most mature 328 spruce trees within the sample dataset would accumulate more foliage mass for a given increase 329 in crown length, leading to variable allometric scaling. For aspen, we also expected whole crown 330 foliage mass to show variable scaling with crown length. This was based on the general 331 understanding that age-related decline in foliage mass usually appears soon after the peak in 332 mean annual increment for shade intolerant species (Satoo 1962), and was previously used to 333 explain a reduction in foliage area in aspen (Lieffers and Stadt 1994).

334 For spruce, the finding contrary to our expectations suggests that this species employs a 335 strategy of carbon allocation which accounts for the retention of old needles and adjusts the rate 336 of production of new foliage in order to maintain a constant relationship with the vertical growth 337 of the crown. Moreover, this strategy of carbon allocation appears to be maintained beyond the 
338 peak mean annual growth of spruce given that the oldest trees we sampled were approximately

339150 years old. Although the findings are contrary to our expectations, similar trends were found

340 in Norway spruce, a species which displays a shade-tolerance similar to that of white spruce

341 (Kantola and Mäkelä 2004). However, it should be noted that Kantola and Mäkelä (2004) did not

342 explicitly test the possibility that a VAR model would have better suited their data.

As was the case for spruce, aspen showed a constant allometric relationship between foliage

344 mass and crown length. For aspen, it appears that despite age-related effects such as increased

345 incidence of disease and reduced stomatal conductance (Smith et al. 2011), carbon continues to

346 be allocated in a manner which maintains the same amount of foliage production for a given

347 increase in crown length. Similarly, Ilomäki et al (2003) reported a constant allometric

348 relationship between foliage mass and crown length for silver birch. However, as was previous

349 noted, there was no indication that Ilomäki et al. (2003) explicitly tested for a variable allometric

350 relationship.

351 Supposing that the full crown of both spruce and aspen are exposed to sunlight, then the

352 relative rates of growth for foliage mass and crown length should, in theory, be in response to the

353 need to regulate self-shading (Okerblom and Kellomaki 1982). In such a case, a constant

354 allometric relationship between foliage mass and crown length will be one that provides the

355 optimal compromise between the benefits of increased foliage mass (i.e., increased

356 photosynthesis) and the increased respiration costs that come with maintaining the structures to

357 support a larger crown (Mäkelä and Sievänen 1992). For aspen, one can argue in support of this

358 supposition given that its growth strategy is to maintain the near entirety of the crown above that

359 of competing vegetation. It is less defendable for white spruce, however, where a large

360 proportion of the crown lies within the shade cast by competitors and is therefore, less 
361 photosynthetically active (Schoonmaker et al. 2014). Consequently, competition from

362 neighbouring trees is also likely to be an important factor driving size-related changes in foliage

363 growth. Indeed, bias across Bal in the residuals resulting from the CAR model in spruce

364 indicated that competition from neighbouring trees had an effect on the relationship between

365 whole crown foliage mass and crown size beyond that posed by self-shading. was low for both spruce and aspen. For the shade tolerant Norway spruce, Kantola and Mäkelä (2006) reported a value of 1.78. A value of in the range of 2-3 was reported by Mäkelä and

369 Sievänen (1992) for open grown Scots pine and red pine, both shade-intolerant species. For

370 Silver birch, also a shade intolerant species, Ilomäki et al. (2003) reported an exponent parameter

371 of 2.62. It is likely that differences in site fertility and local climate are at least partially

372 responsible for the observed discrepancies and thus, direct comparison is not possible.

373 Nevertheless, it was interesting to note that the aforementioned studies used trees from either 374 open grown or evenly spaced, single-species, managed stands. Within the unmanaged mixed375 species stands sample for the current study, greater heterogeneity of within canopy light levels 376 and increased competition for light may possibly explain why the allometric exponents we found 377 were low relative to those reported in other studies.

378 Within-crown scaling between foliage mass and crown length

379 Although whole crown scaling between foliage mass and crown length was constant, there 380 were significant shifts in the allocation of foliage within the crown. For example, within-crown 381 scaling in spruce revealed that the top sections of the crown accumulate foliage mass faster with 382 increasing tree size than sections in the lower half of the crown. As suggested by Mäkelä and 
383 Vanninen (1998), this implies that there is a shift in the allocation of growth higher up the tree as 384 trees get bigger.

385 In the top $25 \%$ of the crown, the accumulation of foliage with increasing crown length was

386 largely unrelated to the competitive status of the tree $(\mathrm{Bal})$. Shade cast by neighbouring 387 competitors, therefore, appears has little effect on the tops of spruce trees. Similar results were 388 reported by Kantola and Mäkelä (2004), where the allometric relationship between foliage mass 389 and crown length in the top 5m of Norway spruce crowns was unaffected by tree age or 390 competition.

391 For aspen, the within-crown sections showed greater similarity in terms of how foliage mass 392 accumulated with increasing crown length. Although foliage mass accumulated slightly faster in 393 the middle section of aspen crowns, competition from neighbouring trees appeared to have little 394 effect on all crown sections. This seems to confirm our earlier suggestion that scaling of foliage 395 mass with crown length in aspen is largely driven by the need to control self-shading. It remains 396 unclear, however, why the allometric scaling exponents for all crown sections were much lower 397 than the expected value for open grown trees. Greater investment into branch wood production 398 and a decreased foliage production during drought years may be at least partially responsible for 399 this discrepancy.

400 Whole crown foliage mass from pipe model theory

401 Mäkelä (1997) notes that the assumption of a linear relationship between whole crown 402 foliage mass and $A s_{\mathrm{cb}}$ will hold on average, but is expected to show some deviation. Deviations 403 may arise through differences in tree size, competition or other environmental factors (Mäkelä 404 and Vanninen 1998). For the current study, we accounted for potential effects of tree size by 405 examining the relationship between foliage mass and $A s_{\mathrm{cb}}$ separately for different diameter 
classes. While our use of diameter classes would have also captured some competition-related effects, one would need to examine the relationship across different measures of competition (e.g. crown ratio or $\mathrm{Bal}$ ) in order to fully account for such effects.

Viewed within context described by Mäkelä (1997), the results of the equivalence testing on white spruce are in line with expectations. That is, for the full dataset, the regions of equivalence to reject the hypothesis that model predictions are both biased and dissimilar, were within the $25 \%$ limit suggested by Wellek (2003). However, for any one diameter class, we can expect considerable dissimilarity between observed and predicted values. While this latter point raises questions regarding the robustness of the pipe model, it must be weighed against the superior performance of the pipe model relative to the regionally calibrated DBH and height based equations. This finding is in accordance with Lehtonen (2005) where is was reported that the basal area of the stem at crown base was a better predictors of foliage mass than DBH or DBH and height-based equations for Norway spruce and Scots pine. Therefore, we conclude that further efforts to validate the pipe model theory for use on white spruce appears to be warranted.

$$
\text { For aspen, the large regions of equivalence required to reject the null hypothesis of }
$$
dissimilarity for the full dataset as well as for any given diameter class suggest that the pipe model, as was tested here, is not appropriate for this species. That being said, using a pipe-based model to predict foliage mass in aspen should still be considered given its performance relative to that of the regionally calibrated DBH and height-based equations. Mäkelä (2002) proposed a modification of the pipe model which accounts for the gradual transition of heartwood to sapwood, and should be considered at a 'next step' in the evaluation of the pipe model for use on aspen. Alternatively, issues related to the measurement of sapwood in aspen may have influenced our results. For example, swelling of the main stem near the crown base of aspen we 
429 sampled may be a source of bias. Additionally, the visual delineation of sapwood area in aspen

430 was hampered by the frequent occurrence of isolated pockets of sapwood within the heartwood,

431 which were absent in spruce. Similar considerations were also discussed by Mäkelä and

432 Vanninen (2001), who suggest that an examination of the hydraulic capabilities would help

433 explain such discrepancies.

434 Within-crown foliage mass from pipe model theory

435 Our examination of the pipe model ratio within the crowns of spruce and aspen trees

436 provided conflicting results. On the one hand, the ratio was found to be moderately stable over

437 relative position within the crowns of spruce and in the two larger size classes for aspen. One

438 could, therefore, argue that there is evidence to suggest that the pipe model is generally

439 unaffected by factors such as whorl age and light conditions. However, potential effects of

440 hydraulic path length on the pipe model ratio are not well accounted for when using relative

441 position within the crown. The influence of this latter factor on the pipe model ratio is more

442 clearly addressed through an examination of the ratio as a function of absolute height from the

443 ground. That the pipe model ratio did not remain constant with increasing absolute height from

444 the ground, therefore, suggests that hydraulic path length may influence the amount of foliage

445 mass supported by a given area of sapwood.

446 Our findings with respect to hydraulic path length, however, were not consistent with the

447 hydraulic model of crown architecture. The hydraulic model predicts that the ratio of whole

448 crown foliage area to sapwood area at breast height should decrease with increasing tree height

449 (Whitehead and Jarvis 1981; McDowell et al. 2002). It is postulated that in order to maintain

450 leaf-specific hydraulic sufficiency, taller trees require greater sapwood area per foliage area

451 given the longer hydraulic path length and associated gravitational constraints. Whitehead et al. 
452 (1984b), Coyea and Margolis (1992), McDowell et al. (2002) and Mencuccini (2002) all reported

453 decreasing ratios of leaf area to sapwood area with increasing tree size. Furthermore, the

454 hydraulic model predicts that there should be progressively less foliage area per unit sapwood

455 area with increasing distance from the ground. Medhurst and Beadle (2002), for example, found

456 the leaf area to sapwood area ratio to decrease with increasing distance from crown base in

457 Eucalyptus (Eucalyptus nitens). These finding, however, do not necessarily imply that similar

458 trends should be observed if foliage area is replaced by foliage mass (i.e., the pipe model ratio).

459 This is because specific leaf area may increase by a factor of 2 from tree top to crown base.

460 Consequently, using foliage mass in place of foliage area can smooth out the variation of the

461 pipe model ratio along the stem (Valentine 2001). However, for the spruce we examined,

462 specific leaf area did not appear to change significantly within the crown. Therefore, one may

463 argue that the within-crown trends for the pipe model ratio should be similar to those predicted

464 by the hydraulic model. Indeed, Mäkelä and Vanninen (2001) found the pipe model ratio to

465 decrease from crown base to tree apex for Scots pine. In contrast, for the current study we found

466 the pipe model ratio to increase with increasing distance from the ground for spruce. For aspen,

467 specific leaf area was found to increase with increasing depth from crown apex for all diameter

468 classes. If anything, this should have reduced our ability to detect any significant within crown

469 trends in the pipe model ratio (Valentine 2001). To the contrary, we detected an increasing trend

470 in the pipe model ratio over increasing distance from the ground.

471 An increasing pipe model ratio with increasing distance from the ground tree is not without

472 precedence. At the whole-crown level, Mokany et al. (2003) and Schneider et al. (2008) both

473 reported an increase in the pipe model ratio with increasing tree size for alpine ash (Eucalyptus

474 delegatensis R.T. Baker) and jack pine, respectively. Furthermore, McDowell et al. (2002) noted 
475 an increasing pipe model ratio with increasing tree height in Norway spruce and Balsam fir

476 [Abies balsamea (L.) Mill.]. Within the crown, Schneider et al. (2011) found that the pipe model

477 ratio decreased with increasing distance from tree apex in Jack pine sampled at three different

478 sites in eastern Canada. They rationalized that differences in the turnover rates of sapwood and

479 foliage could explain the trends they observed. Specifically, they argued that the presence of

480 heartwood in older branches and the re-activation of disused sapwood near crown base leads to

481 greater hydraulic inefficiency lower in the crown, which in turn causes the pipe model ratio to be

482 lower near crown base. However, under this hypothesis we would have expected trends for the

483 within-crown pipe model ratio to show a significant nonlinear relationship with relative depth

484 into the crown for trees in the larger diameter classes. Increased sapwood permeability and soil-

485 to-leaf water potential difference have been cited as possible mechanisms that could explain an

486 increase in pipe model ratio with tree size, although the current set of arguments in favour of

487 these mechanisms is not convincing (McDowell et al. 2002). Leaf specific conductivity, which

488 measures the ability to supply water to unit of foliage, is assumed to be constant across

489 increasing tree size according to the hydraulic path length theory. However, Mokany et al.

490 (2003) found that leaf specific conductivity increased with tree size and, therefore, could explain

491 increases in the pipe model ratio with increasing tree height. Despite the findings that lend

492 support to our current set of results, an examination of leaf specific conductivity in spruce and

493 aspen would be needed to explore the potential link to the within-crown trends for the pipe

494 model ratio we observed.

495 We found the relationship between the pipe model ratio and distance from ground varied by

496 diameter class for spruce but not for aspen. This suggests that for spruce, there is greater size

497 dependency in the relative rates of increase between foliage mass and sapwood area within the 
498

499

500

501

502

503

504

505

506

507

508

509

510

511

512 area (or vice versa) is desired.

513 Conclusion

514

515

516

517 hold on average for spruce. However, there are concerns over the precision in the estimates of

518 foliage mass given the model's poor performance for any single diameter class. For aspen, tests

519 of the pipe model were not convincing. Thus, we conclude that if the Crobas model is to be used

520 within larger area represented by our study sites, consideration must first be given as to how 
521 sapwood is measured as well as how adjustments to the pipe model could improve predictions

522 across all tree sizes. With respect to the latter, this may include the use of additional tree- or

523 stand-level covariates as suggested by Schneider et al. (2008) or a modification to accommodate

524 the gradual transition of sapwood to heartwood as proposed by Mäkelä (2002). Finally, for the

525 relationships that we examined, inconsistencies between the trends seen at the whole-crown level

526 and those seen at the within-crown level were noted. Specifically, those at the whole-crown level

527 appeared far more regular than those at the within-crown level. This feature has been also noted

528 by Mäkelä and Vanninen (2001) and Schneider et al. (2008; 2011). Testing the adjustments that

529 have been suggested to reconcile these differences would be the next logical step.

530 Acknowledgments

531 The work presented in this paper was completed while the lead author was a member of the

532 Forest Value Network/Projet Forêt Valeur. We gratefully acknowledge the Natural Sciences and

533 Engineering Research Council of Canada, who provided financial support for this research

534 project through funding of ForValueNet Stategic Network. Furthermore, we wish to thank the

535 numerous field and lab assistants who contributed to the collection of data used in the analyses.

536 Finally, we very grateful to Dr. Harry Valentine and one anonymous reviewer for their

537 constructive comments which helped elevate the manuscript. 


\section{References}

Alberta Sustainable Resource Development. 2005. Permanent sample plot field procedures manual. Public Lands and Forest Division, Forest Management Branch, Edmonton, Alberta, 30p.

Alemdag, I.S. 1984. Total tree and merchantable stem biomass equations for Ontario hardwoods. Can. For. Ser. Pi-X-46, 54 p.

Baldwin, V.C., Peterson, K.D., Burkhart, H.E., Amateis, R.L., and Dougherty, P.M. 1997. Equations for estimating loblolly pine branch and foliage weight and surface area distributions. Can. J. of For. Res. 27: 918-927.

Beckingham, J.D., and Archibald, J.H. 1996. Field guide to ecosites of northern Alberta.

Berninger, F., and Nikinmaa, E. 1994. Foliage area - sapwood area relationships of Scots pine (Pinus sylvestris) trees in different climates. Can. J. For. Res. 24: 2263-2268.

Berninger, F., Coll, L., Vanninen, P., Mäkelä, A., Palmroth, S., and Nikinmaa, E. 2005. Effects of tree size and position on pipe model ratios in Scots pine. Can. J. of For. Res. 35: 12941304.

Ceulemans, R., Stettler, R., Hinckley, T., Iserbrands, J., and Heilman, P. 1990. Crown Architecture of Populus Clones as Determined by Branch Orientation and Branch Characteristics. Tree Physiol. 7: 157-167. 
Coyea, M.R., and Margolis, H.A. 1992. Factors Affecting the Relationship between Sapwood Area and Leaf-Area of Balsam Fir. Can. J. of For. Res. 22: 1684-1693.

Davidson, R.L. 1969. Effect of root/leaf temperature differentials on root/shoot ratios in some pasture grasses and clover. Annals of Botany 33: 561-569.

Duursma, R.A., Mäkelä, A., Reid, D.E.B., Jokela, E.J., Porte, A.J., and Roberts, S.D. 2010. Selfshading affects allometric scaling in trees. Funct. Ecol. 24: 723-730.

Eckmullner, O., and Sterba, H. 2000. Crown condition, needle mass, and sapwood area relationships of Norway spruce (Picea abies). Can. J. of For. Res. 30: 1646-1654.

Geron, C.D., and Ruark, G.A. 1988. Comparison of constant and variable allometric ratios for predicting foliar biomass of various tree genera. Can. J. of For. Res. 18: 1298-1304.

Gilmore, D.W., Seymour, R.S., and Maguire, D.A. 1996. Foliage-sapwood area relationships for Abies balsamea in central Maine, USA. Can. J. of For. Res. 26: 2071-2079.

Ilomäki, S., Nikinmaa, E., and Mäkelä, A. 2003. Crown rise due to competition drives biomass allocation in silver birch. Can. J. of For. Res. 33: 2395-2404.

Kaipiainen, L.; Hari, P., 1985: Consistencies in the structure of Scots pine. Crop physiology of forest trees. Proceedings of an international conference on managing forest trees as cultivated plants, held in Finland, 23-28 July 1984: 31-37

Kantola, A., and Mäkelä, A. 2004. Crown development in Norway spruce [Picea abies (L.) Karst.]. Trees-Structure and Function 18: 408-421. 
Kantola, A., and Mäkelä, A. 2006. Development of biomass proportions in Norway spruce (Picea abies [L.] Karst.). Trees-Structure and Function 20: 111-121.

Kantola, A., Mäkinen, H., and Mäkelä, A. 2007. Stem form and branchiness of Norway spruce as a sawn timber - Predicted by a process based model. For. Ecol. Manage. 241: 209-222.

Kittredge, J. 1944. Estimation of the amount of foliage of trees and stands. J. For. 42: 905-912.

Lehtonen, A. 2005. Estimating foliage biomass in Scots pine (Pinus sylvestris) and Norway spruce (Picea abies) plots. Tree Physiol. 25: 803-811.

Lieffers, V.J., and Stadt, K.J. 1994. Growth of Understory Picea-Glauca, CalamagrostisCanadensis, and Epilobium-Angustifolium in Relation to Overstory Light Transmission. Can. J. of For. Res. 24: 1193-1198.

Mäkelä, A., and Sievänen, R. 1992. Height Growth Strategies in Open-Grown Trees. J. Theor. Biol. 159: 443-467.

Mäkelä, A. 1997. A carbon balance model of growth and self-pruning in trees based on structural relationships. For. Sci. 43: 7-24.

Mäkelä, A., and Vanninen, P. 1998. Impacts of size and competition on tree form and distribution of aboveground biomass in Scots pine. Can. J. of For. Res. 28: 216-227.

Mäkelä, A., Landsberg, J., Ek, A.R., Burk, T.E., Ter-Mikaelian, M., Agren, G.I., Oliver, C.D., and Puttonen, P. 2000. Process-based models for forest ecosystem management: current state of the art and challenges for practical implementation. Tree Physiol. 20: 289-298. 
Mäkelä, A., and Vanninen, P. 2001. Vertical structure of Scots pine crowns in different age and size classes. Trees-Structure and Function 15: 385-392.

Mäkelä, A. 2002. Derivation of stem taper from the pipe theory in a carbon balance framework. Tree Physiol. 22: 891-905.

Mäkelä, A., and Valentine, H.T. 2006. Crown ratio influences allometric scaling in trees. Ecology 87: 2967-2972.

Manning, G.H., M.R.C. Massie and J. Rudd. 1984. Metric single-tree weight tables for the Yukon Territory. Inf. Rep. BC-X-250. Environment Canada, Canadian Forestry Service, Pacific Forest Research Centre, Victoria, BC, 60 p.

McCulloh, K., Sperry, J.S., Lachenbruch, B., Meinzer, F.C., Reich, P.B., and Voelker, S. 2010. Moving water well: comparing hydraulic efficiency in twigs and trunks of coniferous, ringporous, and diffuse-porous saplings from temperate and tropical forests. New Phytol. 186: 439-450.

McDowell, N., Barnard, H., Bond, B., Hinckley, T., Hubbard, R., Ishii, H., Kostner, B., Magnani, F., Marshall, J., Meinzer, F., Phillips, N., Ryan, M., and Whitehead, D. 2002. The relationship between tree height and leaf area: sapwood area ratio. Oecologia 132: 12-20.

Medhurst, J.L., and Beadle, C.L. 2002. Sapwood hydraulic conductivity and leaf area - sapwood area relationships following thinning of a Eucalyptus nitens plantation. Plant Cell and Environment 25: 1011-1019. 
Mencuccini, M. 2002. Hydraulic constraints in the functional scaling of trees. Tree Physiol. 22: 553-565.

Okerblom, P., and Kellomaki, S. 1982. Effect of Angular-Distribution of Foliage on LightAbsorption and Photosynthesis in the Plant Canopy - Theoretical Computations. Agricultural Meteorology 26: 105-116.

Pinheiro, J., Bates, D., DebRoy, S., Sarkar, D., and R Core Team 2015 nlme: Linear and Nonlinear Mixed Effects Models. R package version 3.1-120.

R Core Team 2013. R: A Language and Environment for Statistical Computing. R Foundation for Statistical Computing, Vienna, Austria. URL: http://.R-project.org.

Regent Instruments Inc. 2003. Image analysis software (http://www.regentinstruments.com). Québec, Canada.

Robinson, A.P., Duursma, R.A., and Marshall, J.D. 2005. A regression-based equivalence test for model validation: shifting the burden of proof. Tree Physiol. 25: 903-913.

Ruark, G.A., Martin, G.L., and Bockheim, J.G. 1987. Comparison of Constant and Variable Allometric Ratios for Estimating Populus Tremuloides Biomass. For. Sci. 33: 294-300.

Satoo, T. 1962. Notes on Kittredge's method of estimation of amount of leaves of forest stand. Jour Japanese Forest Soc 44: 267-272. 
Sattler, D.F., Comeau, P. G., and Achim, A. 2014. Within-tree patterns of wood stiffness for white spruce (Picea glauca) and trembling aspen (Populus tremuloides). Can. J. For. Res. 44: 162-171. dx.doi.org/10.1139/cjfr-2013-0150

Schneider, R., Zhang, S.Y., Swift, D.E., Begin, J., and Lussier, J. 2008. Predicting selected wood properties of jack pine following commercial thinning. Can. J. of For. Res. 38: 2030-2043.

Schneider, R., Berninger, F., Ung, C., Mäkelä, A., Swift, D.E., and Zhang, S.Y. 2011. Within crown variation in the relationship between foliage biomass and sapwood area in jack pine. Tree Physiol. 31: 22-29.

Schoonmaker, A.L., Lieffers, V.J., and Landhaeusser, S.M. 2014. Uniform versus Asymmetric Shading Mediates Crown Recession in Conifers. PLoS One 9: e104187.

Shinozaki, K.K., Yoda, K., Hozumi, K., and Kira, T. 1964. A quantitative analysis of plant form — the pipe model theory. 1. Basic analyses. Jpn. J. Ecol. 14: 97-105.

Smith, E.A., Collette, S.B., Boynton, T.A., Lillrose, T., Stevens, M.R., Bekker, M.F., Eggett, D., and St Clair, S.B. 2011. Developmental contributions to phenotypic variation in functional leaf traits within quaking aspen clones. Tree Physiol. 31: 68-77.

Valentine, H.T. 2001. Influence of vertical foliage structure on the distribution of stem crosssectional area increment in western hemlock and balsam fir [For. Sci. 46(1):86-94] Comment. For. Sci. 47: 115-116.

Valentine, H.T. and Mäkelä, A. 2005. Bridging process-based and empirical approaches to modeling tree growth. In Tree Physiology, JUL, Edited by Anonymous pp. 769-779. 
Waring, R.H., Schroeder, P.E., and Oren, R. 1982. Application of the Pipe Model-Theory to Predict Canopy Leaf-Area. Can. J. of For. Res. 12: 556-560.

Wellek, S. 2003. Testing statistical hypotheses of equivalence. Chapman and Hall/CRC. 284 pp.

Whitehead, D. and P.G. Jarvis. 1981. Coniferous forests and plantations. In Water Deficits and Plant Growth. Vol. VI. Ed. T.T. Kozlowski. Academic Press, New York, pp 49-152.

Whitehead, D., Jarvis, P.G., and Waring, R.H. 1984a. Stomatal Conductance, Transpiration, and Resistance to Water-Uptake in a Pinus-Sylvestris Spacing Experiment. Can. J. of For. Res. 14: $692-700$.

Whitehead, D., Edwards, W.R.N., and Jarvis, P.G. 1984b. Conducting Sapwood Area, Foliage Area, and Permeability in Mature Trees of Picea-Sitchensis and Pinus-Contorta. Can. J. of For. Res. 14: 940-947.

Whitehead, D., and Gower, S.T. 2001. Photosynthesis and light-use efficiency by plants in a Canadian boreal forest ecosystem. Tree Physiol. 21: 925-929.

Zeide, B., and Pfeifer, P. 1991. A Method for Estimation of Fractal Dimension of Tree Crowns. For. Sci. 37: 1253-1265. 


\section{Tables}

Table 1. Means (with standard deviation in parentheses) by diameter class (Diam class) of select variables for the sampled spruce and aspen trees.

\begin{tabular}{|c|c|c|c|c|c|c|c|c|}
\hline Diameter class & $\mathrm{DBH}(\mathrm{cm})$ & Height (m) & $\mathrm{Cl}(\mathrm{m})$ & $W_{\mathrm{f}}(\mathrm{Kg})$ & $A_{\mathrm{cb}}\left(\mathrm{cm}^{2}\right)$ & $R p$ & $\mathrm{n}$ & Age \\
\hline \multicolumn{9}{|l|}{ Spruce } \\
\hline Diam class $1(<16 \mathrm{~cm})$ & $15.07(0.86)$ & $13.97(1.87)$ & $10.72(1.94)$ & $9.92(3.49)$ & $99.78(29.23)$ & $0.0998(0.015)$ & 11 & 125 \\
\hline Diam class $2(16.0-22.5 \mathrm{~cm})$ & $20.56(1.72)$ & $18.01(2.45)$ & $11.73(2.04)$ & $16.12(6.35)$ & $145.38(74.75)$ & $0.1171(0.027)$ & 14 & 115 \\
\hline Diam class3 $(22.5-30.0 \mathrm{~cm})$ & $25.72(2.21)$ & $20.92(3.94)$ & $13.22(3.11)$ & $20.09(5.93)$ & $152.95(55.51)$ & $0.1461(0.045)$ & 15 & 68 \\
\hline Diam class4 $(30.0-36.5 \mathrm{~cm})$ & $32.12(2.16)$ & $26.64(2.75)$ & $16.09(4.04)$ & $29.69(12.39)$ & $190.23(87.22)$ & $0.1635(0.034)$ & 10 & 64 \\
\hline Diam class5 $(36.5-45.5 \mathrm{~cm})$ & $41.28(2.23)$ & $31.64(1.67)$ & $19.71(4.56)$ & $39.64(12.46)$ & $241.88(94.46)$ & $0.1729(0.041)$ & 15 & 45 \\
\hline \multicolumn{9}{|l|}{ Aspen } \\
\hline Diam class1 $(<16 \mathrm{~cm})$ & $14.54(1.09)$ & $18.89(2.31)$ & $6.81(1.46)$ & $1.26(0.43)$ & $42.74(13.31)$ & $0.0296(0.004)$ & 15 & 65 \\
\hline Diam class2 $(16.0-22.0 \mathrm{~cm})$ & $18.83(1.54)$ & $20.52(1.87)$ & $7.62(1.58)$ & $2.01(0.43)$ & $69.16(22.56)$ & $0.0303(0.011)$ & 11 & 61( \\
\hline Diam class3 $(22.0-28.0 \mathrm{~cm})$ & $25.37(1.82)$ & $24.72(2.42)$ & $9.68(1.31)$ & $3.34(1.10)$ & $131.18(45.17)$ & $0.0269(0.008)$ & 14 & 39 \\
\hline Diam class4 $(28.0-35.0 \mathrm{~cm})$ & $31.38(1.89)$ & $26.06(2.64)$ & $8.00(2.27)$ & $3.87(1.19)$ & $136.76(56.71)$ & $0.0312(0.013)$ & 6 & 30 \\
\hline
\end{tabular}


Table 2. Symbols and associated description of variables used for the analyses.

\begin{tabular}{ll}
\hline Variable Symbol & Description \\
\hline$W_{\mathrm{f}}$ & Foliage mass $(\mathrm{Kg})$ \\
$A_{\mathrm{cb}}$ & Sapwood area at crown base $\left(\mathrm{cm}^{2}\right)$ \\
$R a_{\mathrm{k}}$ & Ratio of cumulative $\mathrm{Wf}$ to $\mathrm{CPA}$ at the base of crown quarter section $k$ \\
$R p_{\mathrm{k}}$ & Ratio of cumulative $\mathrm{Wf}$ to As at the base of crown quarter section $k$ \\
$C l$ & Length of live crown $(\mathrm{m})$ \\
$R d i n c$ & Relative crown depth from tree apex $(0=$ crown apex, $1=$ crown base $)$ \\
$H_{\mathrm{k}}$ & Distance from ground to base of crown section $k(\mathrm{~m})$ \\
$C r d p t h$ & Crown depth from tree apex $(\mathrm{m})$ \\
$S L A$ & Specific leaf area $\left(\mathrm{cm}^{2} / \mathrm{g}\right)$ \\
Diam class & Diameter class $(1 \text { to } 5 \text { for spruce; } 1 \text { to } 4 \text { for aspen })^{1}$ \\
$B a l$ & Basal area of larger trees $\left(\mathrm{m}^{2}\right.$ ha $\left.{ }^{-1}\right)$ \\
\hline
\end{tabular}

${ }^{1}$ See Table 1 for diameter class ranges used for each species. 
Table 3. Estimated parameters (standard error, SE, in parentheses) and fit statistics from the constant and variable allometric models (CAR and VAR; Equation 1 and 2 in text) fitted to spruce and aspen data. For each species, the $\mathrm{CAR}$ and VAR models were fitted as a function of crown length $(\mathrm{Cl} ; \mathrm{m})$.

\begin{tabular}{|c|c|c|c|c|c|c|c|}
\hline & \multicolumn{3}{|c|}{ Parameters (SE) } & \multirow[b]{2}{*}{ Adj. $-R^{2}$} & \multirow[b]{2}{*}{$\begin{array}{l}\text { Likelihood } \\
\text { ratio test }^{1}\end{array}$} & \multirow[b]{2}{*}{ p-value } & \multirow[b]{2}{*}{ RMSE } \\
\hline & $\delta_{0}$ & $\delta_{1}$ & $\delta_{2}$ & & & & \\
\hline \multicolumn{8}{|c|}{ Spruce } \\
\hline CAR & $0.47(0.18)$ & $1.45(0.14)$ & - & $61 \%$ & - & - & 8.41 \\
\hline $\begin{array}{l}\text { VAR } \\
\text { Aspen }\end{array}$ & $0.09(0.15)$ & $2.41(0.95)$ & $-0.06(0.06)$ & $61 \%$ & 1.101 & 0.2939 & 8.36 \\
\hline CAR & $0.15(0.09)$ & $1.29(0.28)$ & - & $31 \%$ & - & - & 1.02 \\
\hline VAR & $0.19(0.48)$ & $1.07(2.21)$ & $0.02(0.27)$ & $30 \%$ & 0.01 & 0.917 & 1.03 \\
\hline
\end{tabular}

${ }^{1}$ Likelihood ratio tests and associated p-value were the result of comparing the CAR to the VAR model. 
Table 4. Parameter estimates (standard error, SE, in parentheses) for Equations 3a to 3d, describing the relationship between foliage mass and crown length for the four crown sections $(\mathrm{k}=$ section $1,2,3,4)$. The asterisk $(*)$ denotes a significant difference between $\delta_{0}$ (from Equation 1) and $\varphi_{\mathrm{k}}$ (from Equations $3 \mathrm{a}$ to $3 \mathrm{~d}$ ).

\begin{tabular}{cccc}
\hline & $\varphi_{\mathrm{k}}(\mathrm{SE})$ & p-value & Adj.- $\boldsymbol{R}^{\mathbf{2}}$ \\
\hline Spruce & & & \\
Top - $25 \%(k=1)$ & $0.89 *(0.05)$ & $<0.05$ & $63 \%$ \\
$25-50 \%(k=2)$ & $0.68 *(0.04)$ & $<0.05$ & $56 \%$ \\
$50-75 \%(k=3)$ & $0.44(0.02)$ & $<0.05$ & $11 \%$ \\
$75 \%$ - Crown base $(k=4)$ & $0.24 *(0.02)$ & $<0.05$ & $9 \%$ \\
\cline { 2 - 4 } & $\varphi_{\mathrm{k}}(\mathbf{S E})$ & $\mathbf{p - v a l u e}$ & $\mathbf{A d j}-\boldsymbol{R}^{\mathbf{2}}$ \\
\hline Aspen & & & \\
Top - 25\% $(k=1)$ & $0.11 *(0.07)$ & $<0.05$ & $16 \%$ \\
$25-50 \%(k=2)$ & $0.18(0.01)$ & $<0.05$ & $50 \%$ \\
$50-75 \%(k=3)$ & $0.21 *(0.02)$ & $<0.05$ & $23 \%$ \\
$75 \%$ - Crown base $(k=4)$ & $0.14(0.02)$ & $<0.05$ & $5 \%$ \\
\hline
\end{tabular}


Table 5. Results of equivalence tests on prediction of from the fitted pipe model (Equation 4) and from published DBH and Height-based equations [Spruce = Manning (1984); Aspen = Alemdag (1984)]. Equivalence tests of predictions from the fitted pipe model are for the full dataset (all DBH classes) and by individual DBH classes (diam class 1 to 5 for spruce and diam class 1 to 4 for aspen).

\begin{tabular}{|c|c|c|c|c|c|c|}
\hline \multirow[b]{2}{*}{ Data Grouping } & \multicolumn{6}{|c|}{ Equivalence tests } \\
\hline & $\begin{array}{c}\text { CI } \\
\text { (Intercept) }\end{array}$ & $\begin{array}{l}\text { Region of } \\
\text { Similarity }\end{array}$ & $\begin{array}{l}\text { Min. Region of } \\
\text { Equivalence } \\
\text { for Intercept }\end{array}$ & $\begin{array}{c}\text { CI } \\
\text { (Slope) }\end{array}$ & $\begin{array}{l}\text { Region of } \\
\text { Similarity }\end{array}$ & $\begin{array}{l}\text { Min. Region of } \\
\text { Equivalence } \\
\text { for Slope }\end{array}$ \\
\hline Full dataset & $21.77-25.46$ & $21.30-26.03$ & $10 \%$ & $0.76-1.14$ & $0.75-1.25$ & $25 \%$ \\
\hline diam class 1 & $35.33-44.46$ & $22.07-45.85$ & $35 \%$ & $0.24-1.07$ & $0.2-1.8$ & $80 \%$ \\
\hline diam class 2 & $25.94-34.12$ & $17.36-36.05$ & $35 \%$ & $0.59-1.36$ & $0.55-1.45$ & $45 \%$ \\
\hline diam class 3 & $18.50-22.97$ & $18.25-24.69$ & $15 \%$ & $0.06-0.75$ & $0.04-1.9$ & $90 \%$ \\
\hline diam class 4 & $14.77-17.14$ & $14.28-26.53$ & $30 \%$ & $0.44-0.72$ & $0.45-1.55$ & $55 \%$ \\
\hline diam class 5 & $8.82-10.89$ & $8.40-19.61$ & $40 \%$ & $0.36-1.01$ & $0.35-1.65$ & $65 \%$ \\
\hline Manning (1984) & $21.40-25.78$ & $19.08-89.96$ & $65 \%$ & $0.16-0.27$ & $0.15-1.85$ & $85 \%$ \\
\hline Aspen & \multicolumn{6}{|c|}{ Equivalence tests } \\
\hline Data Grouping & $\begin{array}{c}\text { CI } \\
\text { (Intercept) }\end{array}$ & $\begin{array}{l}\text { Region of } \\
\text { Similarity }\end{array}$ & $\begin{array}{l}\text { Min. Region of } \\
\text { Equivalence } \\
\text { for Intercept }\end{array}$ & $\begin{array}{c}\text { CI } \\
\text { (Slope) }\end{array}$ & $\begin{array}{l}\text { Region of } \\
\text { Similarity } \\
\end{array}$ & $\begin{array}{c}\text { Min. Region of } \\
\text { Equivalence } \\
\text { for Slope }\end{array}$ \\
\hline Full dataset & $2.15-2.68$ & $2.06-3.10$ & $20 \%$ & $0.38-0.92$ & $0.35-1.65$ & $65 \%$ \\
\hline diam class 1 & $1.16-1.38$ & $1.06-1.43$ & $15 \%$ & $0.78-1.27$ & $0.7-1.3$ & $30 \%$ \\
\hline diam class 2 & $1.68-2.18$ & $1.41-2.63$ & $30 \%$ & $-0.33-0.56$ & $-0.35-2.35$ & $135 \%$ \\
\hline diam class 3 & $2.84-4.31$ & $2.68-4.99$ & $30 \%$ & $-0.21-1.60$ & $-0.35-2.35$ & $120 \%$ \\
\hline diam class 4 & $3.05-4.00$ & $2.91-4.86$ & $25 \%$ & $-0.13-0.76$ & $-0.2-2.2$ & $120 \%$ \\
\hline Alemdag (1984) & $2.17-2.60$ & $1.41-55.34$ & $90 \%$ & $0.04-0.06$ & $0.03-1.95$ & $100 \%$ \\
\hline
\end{tabular}

Note: Confidence intervals (CI) for the intercept (test of bias) and slope (test of accuracy) were obtained using a non-parametric bootstrap based on 5000 replicates. Regions of similarity, which fall within the CIs, were obtained after determining the minimum region of equivalence at which the null hypothesis of dissimilarity could be rejected. All tests were evaluated at alpha $=0.05$. 
Table 6. Estimated parameters (with standard errors, SE, in parentheses) for the relationship of the pipe model ratio $\left(R p_{k}=\right.$ foliage mass/sapwood area at crown quarter section $\left.k\right)$ as a function of relative depth from crown apex (Rdinc) and as a function of distance from ground $\left(H_{k}\right)$ (see Equation 6).

\begin{tabular}{|c|c|c|c|c|c|c|}
\hline \multirow[t]{2}{*}{ Spruce } & \multicolumn{2}{|c|}{$\begin{array}{c}\text { Model: } R p_{k}=f(R \operatorname{dinc}) \\
\text { Parameters (SE) }\end{array}$} & \multicolumn{3}{|c|}{$\begin{array}{c}\text { Model: } R p_{k}=f\left(H_{k}\right) \\
\text { Parameters }(\mathrm{SE})\end{array}$} & \multirow[b]{2}{*}{ Adj.- $R^{2}$} \\
\hline & $\lambda_{0}{ }^{1}$ & $\lambda_{1}{ }^{1}$ & Adj. $-R^{2}$ & $\lambda_{0}{ }^{1}$ & $\lambda_{1}{ }^{1}$ & \\
\hline diam class 1 & $974.08(78.45)$ & $31.09(97.95)$ & $1 \%$ & 999.98 (56.32) & $-1.05(8.10)$ & $1 \%$ \\
\hline diam class 2 & $1422.27(110.65)$ & $-250.26(123.14)$ & $4 \%$ & $932.31(57.33)$ & $30.38 *(7.71)$ & $19 \%$ \\
\hline diam class 3 & $1535.32(141.64)$ & $-57.72(176.41)$ & $1 \%$ & $1149.96(93.69)$ & $27.30 *(8.91)$ & $16 \%$ \\
\hline diam class 4 & $2048.51(248.21)$ & $-300.09(335.97)$ & $1 \%$ & $1488.18(170.72)$ & $22.09 *(14.45)$ & $5 \%$ \\
\hline diam class 5 & $2117.28(158.99)$ & $-368.84(186.46)$ & $3 \%$ & $1551.73(189.43)$ & $17.24 *(8.72)$ & $6 \%$ \\
\hline \multirow[t]{2}{*}{ Aspen } & \multicolumn{2}{|c|}{ Model $R p_{k}=f(R \operatorname{dinc})$} & & \multicolumn{2}{|c|}{ Model $R p_{k}=f\left(H_{k}\right)$} & \\
\hline & $\lambda_{0}^{1}$ & $\lambda_{1}{ }^{1}$ & Adj. $-R^{2}$ & $\lambda_{0}^{1}$ & $\lambda_{1}^{1}$ & Adj.- $R^{2}$ \\
\hline diam class 1 & $434.55(29.53)$ & $-134.61 *(34.80)$ & $6 \%$ & $287.03(54.18)$ & $3.83(3.58)$ & $1 \%$ \\
\hline diam class 2 & $459.97(57.42)$ & $-150.65 *(69.63)$ & $9 \%$ & $80.77(63.61)$ & $18.62 *(5.42)$ & $1 \%$ \\
\hline diam class 3 & $357.51(43.34)$ & $-66.48(57.66)$ & $1 \%$ & 129.58 (99.69) & $10.00 *(5.17)$ & $8 \%$ \\
\hline diam class 4 & $352.75(75.05)$ & $-35.12(98.97)$ & $1 \%$ & $9.78(135.70)$ & $15.44 *(6.33)$ & $18 \%$ \\
\hline
\end{tabular}

* Denotes parameters that are significantly different from the zero at alpha $=0.05$. 
540 Table 7. Parameters estimates (standard errors, SE, in parentheses) for the relationship describing specific leaf area $541 \quad\left(\mathrm{SLA} ; \mathrm{cm}^{2} / \mathrm{g}\right)$ as a function of crown depth (Crdpth) (Equation 7).

\begin{tabular}{|c|c|c|c|c|}
\hline & \multicolumn{2}{|c|}{ Parameters (SE) } & \multirow[b]{2}{*}{$\begin{array}{c}\text { p- } \\
\text { value }\end{array}$} & \multirow[b]{2}{*}{ Adj.- $R^{2}$} \\
\hline & $\eta_{0}$ & $\eta_{1}$ & & \\
\hline \multicolumn{5}{|l|}{ Spruce } \\
\hline diam class 1 & $56.32(4.91)$ & $0.31(0.77)$ & 0.68 & $<0.05 \%$ \\
\hline diam class 2 & $43.23(2.80)$ & $0.37(0.37)$ & 0.32 & $<0.05 \%$ \\
\hline diam class 3 & $39.54(2.89)$ & $0.31(0.36)$ & 0.39 & $<0.05 \%$ \\
\hline diam class 4 & $37.68(2.57)$ & $0.23(0.27)$ & 0.40 & $<0.05 \%$ \\
\hline \multirow[t]{3}{*}{ diam class 5} & $41.93(3.25)$ & $0.42(0.25)$ & 0.10 & $2 \%$ \\
\hline & \multicolumn{2}{|c|}{ Parameters (SE) } & & \\
\hline & $\eta_{0}$ & $\eta_{1}$ & $\begin{array}{c}\text { p- } \\
\text { value }\end{array}$ & Adj. $-R^{2}$ \\
\hline \multicolumn{5}{|l|}{ Aspen } \\
\hline diam class 1 & $93.33(5.41)$ & $3.88(1.09)$ & $<0.05$ & $10 \%$ \\
\hline diam class 2 & $94.23(6.67)$ & $3.56(1.50)$ & 0.02 & $10 \%$ \\
\hline diam class 3 & $81.48(4.93)$ & $3.73(0.91)$ & $<0.05$ & $25 \%$ \\
\hline diam class 4 & $79.93(7.66)$ & $5.66(1.16)$ & $<0.05$ & $32 \%$ \\
\hline
\end{tabular}


Figure 1.Whole-crown allometry between foliage mass $(\mathrm{Kg})$ and crown length $(\mathrm{m})$ for white spruce (panel a) and aspen (panel b). Lines are predictions from the fitted constant (black lines) and variable (grey lines) allometric equations (Equation 1 and 2, respectively).

Figure 2. Within-crown scaling between foliage mass $(\mathrm{Kg})$ and crown length $(\mathrm{m})$ for quarter sections of the crown (Equation 3). Top panel is for spruce, bottom panel is for aspen.

Figure 3. Pearson residuals from the relationship between foliage mass and crown length in white spruce by crown quarter section (Equation 3 ) plotted against basal area of larger trees $\left(\mathrm{m}^{2} \mathrm{ha}^{-1}\right.$; Bal).

Figure 4. Pearson residuals from the relationship between foliage mass and crown length in aspen by crown quarter section (Equation 3) plotted against basal area of larger trees $\left(\mathrm{m}^{2} \mathrm{ha}^{-1}\right.$; Bal).

Figure 5. Plots describing the relationship for the pipe model ratio $\left(R p_{\mathrm{k}}\right)$ versus: 1$)$ the relative distance from crown apex (Rdinc) (left panel) and 2) the distance from ground $\left(H_{k} ; \mathrm{m}\right)$ (right panel) within the crowns of white spruce. Numbers at the top of each graph correspond to the diameter class (see text). Solid lines are the fitted linear regression (Equation 6).

Figure 6. Plots describing the relationship for the pipe model ratio $\left(R p_{\mathrm{k}}\right)$ versus: 1$)$ the relative distance from crown apex (Rdinc) (left panel) and 2) the distance from ground $\left(H_{k} ; \mathrm{m}\right)$ (right panel) within the crowns of aspen. Numbers at the top of each graph correspond to the diameter class (see text). Solid lines are the fitted linear regression (Equation 6). 
545 Appendix 1

546 Scaling up from branch to tree

547 For both white spruce and aspen, the nonlinear mixed effects model used to obtain estimates of

548 foliage mass at the branch level was:

[A1] $\quad \hat{W}_{\mathrm{f}_{j k l}}=\beta_{1} \times A_{\mathrm{b}, j k l}{\left(\beta_{2}+\mathrm{b}_{2 j}+\mathrm{b}_{2 j k}\right)}^{2} \times \operatorname{Rinc} c_{j k l}^{\left(\beta_{3}+\mathrm{b}_{3 j}+\mathrm{b}_{3 j k}\right)}+\varepsilon_{j k l}$

550 where $A_{b}$ is branch basal area $\left(\mathrm{cm}^{2}\right)$ and Rdinc is the relative distance into the crown from tree apex and

$551 \hat{W}_{\mathrm{f}}$ is foliage mass (in $\mathrm{Kg}$ ) for branch $l$ in tree $k$, nested within plot $j$. The $\beta_{1}, \beta_{2}, \beta_{3}$ are fixed effect

552 parameters, while $b_{2, j}, b_{2, j k}, b_{3, j}$ and $b_{3, j k}$ are the random effects for tree $k$, nested within plot $j$.

553 Independent variables tested in the models were limited to those that were measured on all live branches.

554 A power variance weight structure that was a function of branch basal area was used to account for

555 heteroskedasticity, while autocorrelation was addressed through a continuous autoregressive structure.

556 For spruce, the fixed + random effects explained 68\% (only fixed effects $=57 \%$ ) of the variability in

557 branch-level $\hat{W}_{\mathrm{f}}\left(\mathrm{RMSE}=0.08 \mathrm{Kg} ; \beta_{1}=50.41, \beta_{2}=1.07, \beta_{3}=-0.63\right)$. For aspen, fixed + random effects

558 accounted for $86 \%$ (only fixed effects $=51 \%$ ) of the variability in branch-level $\hat{W}_{\mathrm{f}}(\mathrm{RMSE}=0.03 \mathrm{Kg}$;

$\left.559 \quad \beta_{1}=21.53, \beta_{2}=1.07, \beta_{3}=-1.67\right)$. 

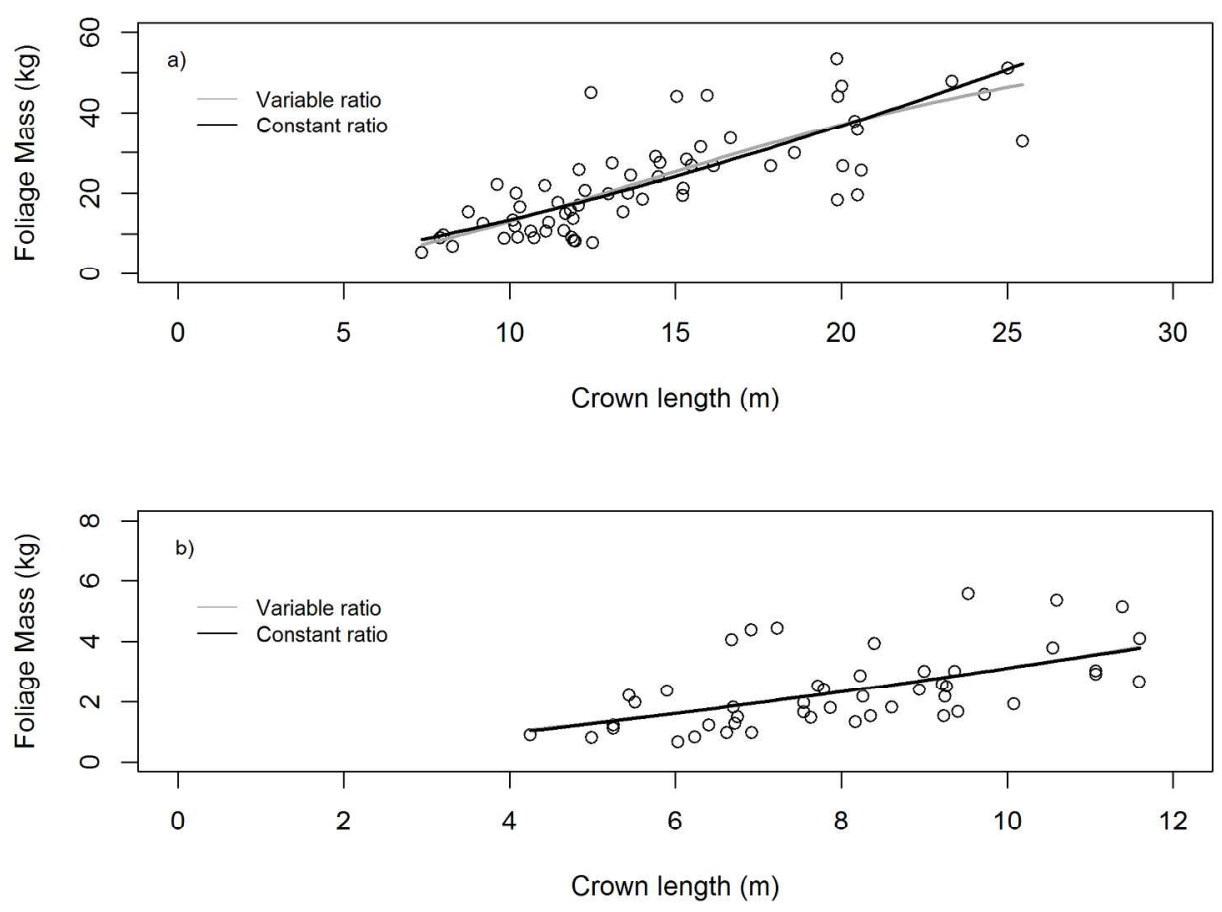

Whole-crown allometry between foliage mass $(\mathrm{Kg})$ and crown length $(\mathrm{m})$ for white spruce (panel $\mathrm{a})$ and aspen (panel b). Lines are predictions from the fitted constant (black lines) and variable (grey lines) allometric equations (Equation 1 and 2, respectively). $203 \times 152 \mathrm{~mm}(300 \times 300$ DPI) 

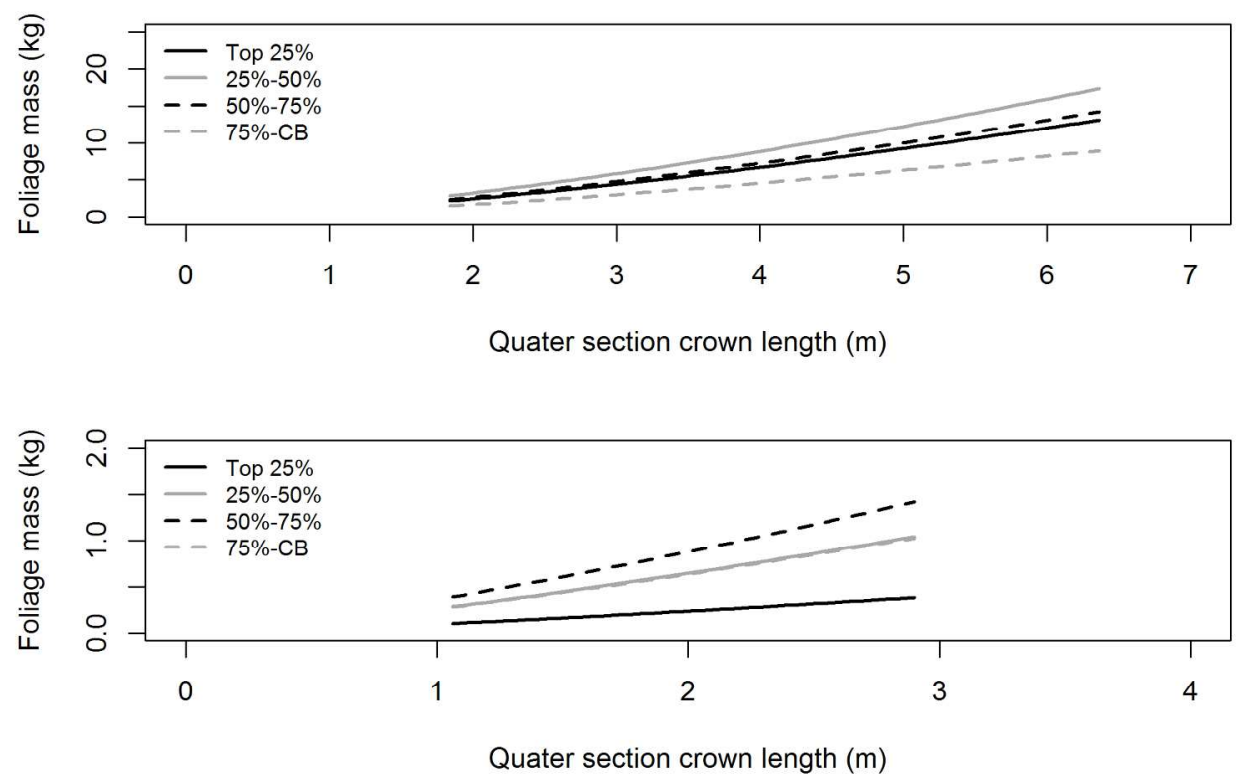

Within-crown scaling between foliage mass $(\mathrm{Kg})$ and crown length $(\mathrm{m})$ for quarter sections of the crown (Equation 3). Top panel is for spruce, bottom panel is for aspen. $198 \times 127 \mathrm{~mm}(300 \times 300$ DPI $)$ 

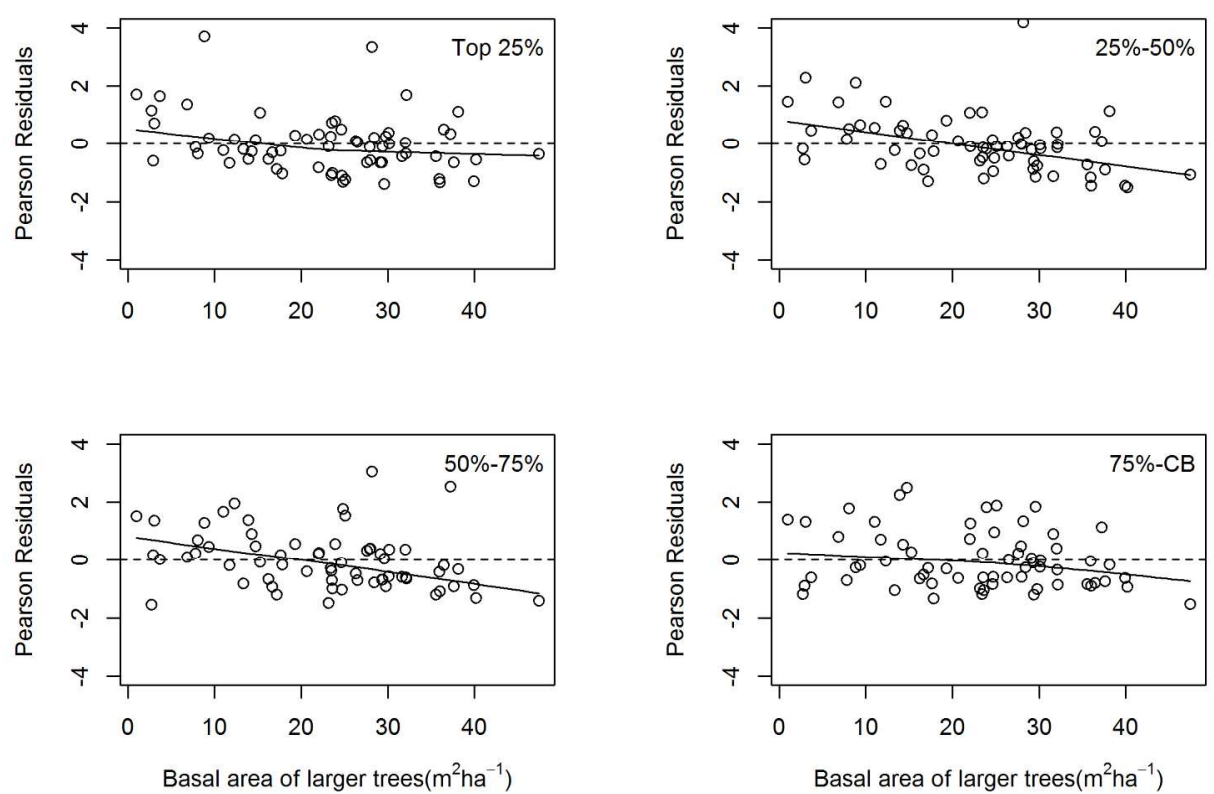

Pearson residuals from the relationship between foliage mass and crown length in white spruce by crown quarter section (Equation 3) plotted against basal area of larger trees $\left(\mathrm{m}^{2} \mathrm{ha}{ }^{-1} ; \mathrm{Bal}\right)$. $198 \times 127 \mathrm{~mm}$ (300 x 300 DPI) 

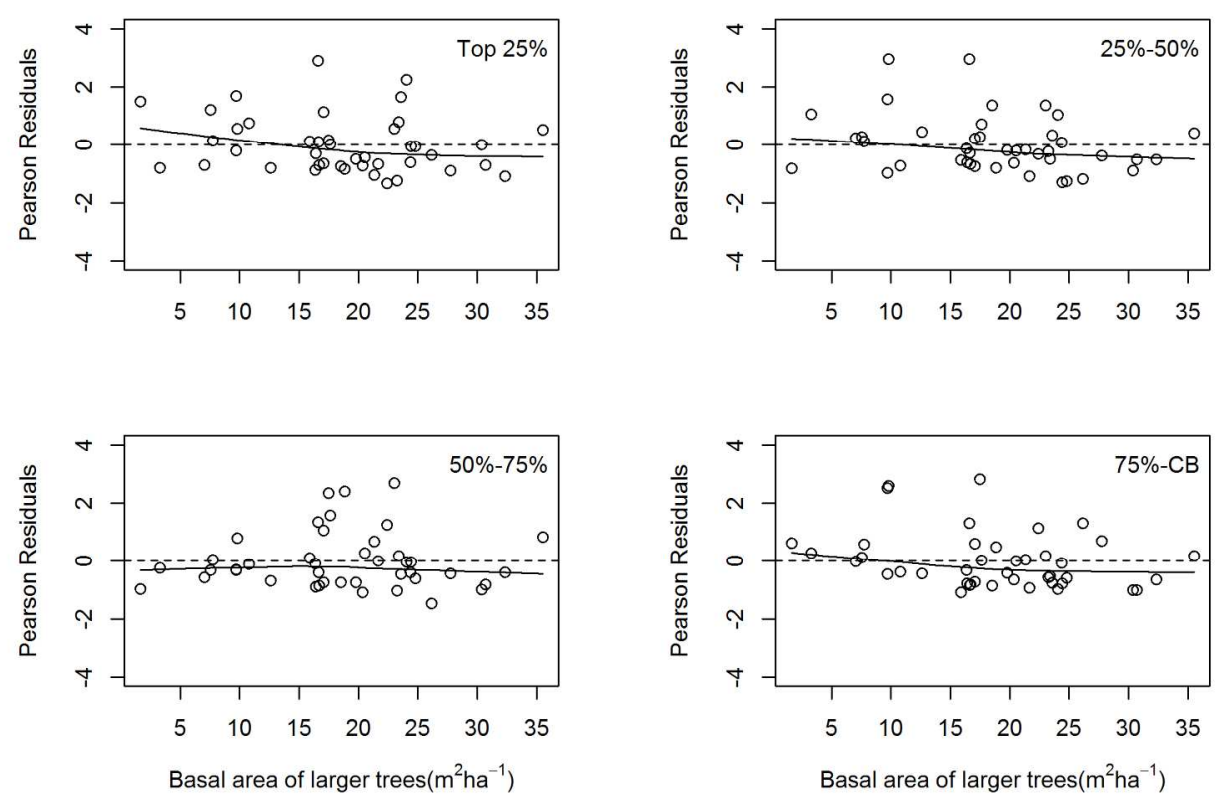

Pearson residuals from the relationship between foliage mass and crown length in aspen by crown quarter section (Equation 3) plotted against basal area of larger trees $\left(\mathrm{m}^{2} \mathrm{ha}^{-1} ; \mathrm{Bal}\right)$. $198 \times 127 \mathrm{~mm}(300 \times 300 \mathrm{DPI})$ 

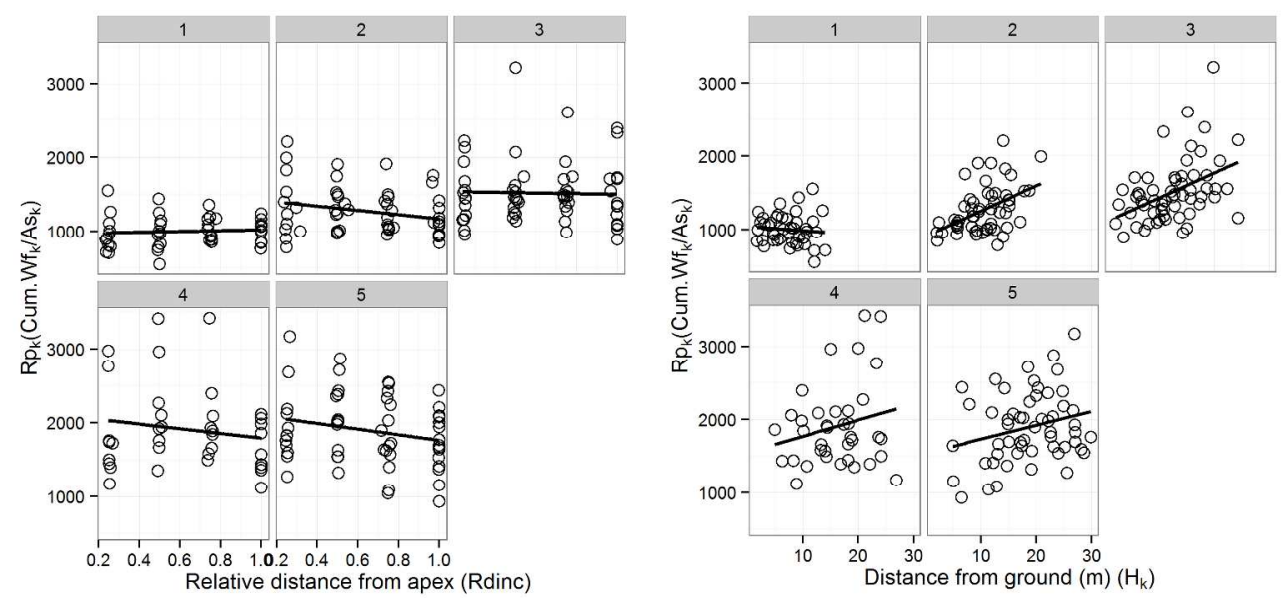

Plots describing the relationship for the pipe model ratio $\left(R p_{k}\right)$ versus: 1$)$ the relative distance from crown apex (Rdinc) (left panel) and 2) the distance from ground $\left(H_{k} ; \mathrm{m}\right)$ (right panel) within the crowns of white spruce. Numbers at the top of each graph correspond to the diameter class (see text). Solid lines are the fitted linear regression (Equation 6).

$254 \times 120 \mathrm{~mm}(300 \times 300 \mathrm{DPI})$ 

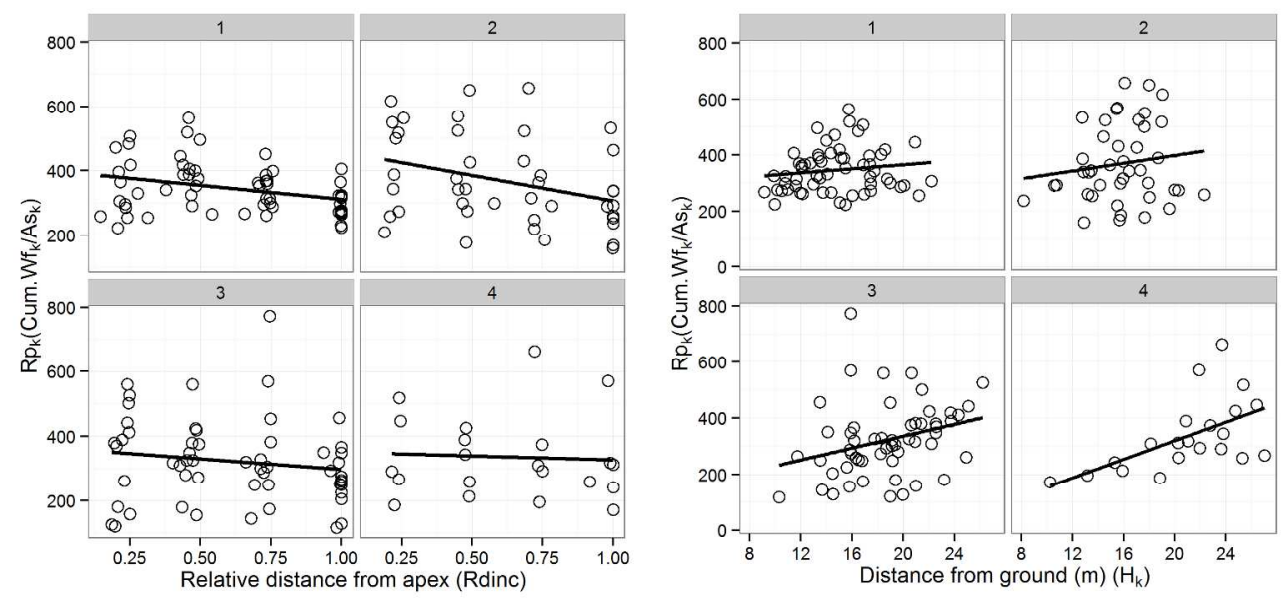

Plots describing the relationship for the pipe model ratio $\left(R p_{\mathrm{k}}\right)$ versus: 1$)$ the relative distance from crown apex (Rdinc) (left panel) and 2 ) the distance from ground $\left(H_{k} ; \mathrm{m}\right)$ (right panel) within the crowns of aspen. Numbers at the top of each graph correspond to the diameter class (see text). Solid lines are the fitted linear regression (Equation 6$)$. $254 \times 120 \mathrm{~mm}(300 \times 300$ DPI) 